\title{
Richard R. Gacek: Ear surgery
}

\section{Springer, 2007, ISBN 978-3-540-77411-2}

\section{Per Møller}

Published online: 13 January 2009

(C) Springer-Verlag 2009

"Otologic procedures that endure are based on a detailed knowledge of the anatomy, physiology, and pathology of the temporal bone." This citation from the very experienced author introduces this book, which presents a systematic text together with $6 \mathrm{CDs}$ of operation movies, covering together 11 chapters of otosurgery and oto-neurosurgery. Photomicrographs are used in the book to underline the clinical problems. The videos are to the point, not too long, and cover a broad field in ear surgery. The book is intended for residents and oto-surgeons in progress, but also experienced ear surgeons, not the least, will enjoy this book and the videos, not because of the quality of pictures, but because of the basic knowledge and skills presented.
The book is short, the video quality could in some strips be better, but tells an interesting story of problems in ear surgery and the solution to some of them.

In many ways, this is a living history book, going only some years back, but already telling the story of the microscopic era of ear surgery. Today, it will for most surgeons take longer to have the same experience as the ear surgeons starting in the 1960s. This book gives the ENT surgeon a better chance to prepare for the unexpected, and to visualize the problems before operations.

\section{P. Møller ( $\square)$}

Department of Otolaryngology/Head and Neck Surgery,

Haukeland University Hospital, 5021 Bergen, Norway

e-mail: per-moe@online.no 